\title{
Caminhos do saber Arukwayene nas águas da história: a emergência da historicidade Palikur em narrativas de memória
}

\author{
Carina Santos Almeida ${ }^{1}$ \\ Elissandra Barros da Silva²
}

\begin{abstract}
RESUMO: Os Palikur-Arukwayene são um povo indígena que vivem em ambos os lados da fronteira entre o Brasil e a Guiana Francesa e, juntamente com Karipuna, GalibiMarworno e Galibi-Kalinã, constituem o que a literatura convencionou chamar de povos indígenas de Oiapoque. Este artigo aborda a emergência da "historicidade" deste povo a partir das narrativas dos sábios Wet e Tebekwe e, ao mesmo tempo, analisa como estes sábios, de forma singular e distinta, são reconhecidos e referenciados por esta sociedade. A "latência" de saberes palikur-arukwayene emerge dos estudos e pesquisas que vem sendo desenvolvidas há alguns anos com o povo e, em decorrência disso, fomentam a (re)escrita da história a partir das interseções com as narrativas de vida, relatos de experiências, transmissão e compartilhamento de conhecimentos dos sábios. Neste percurso, fizemos o registro e documentação de narrativas que possibilitam considerar que muitos dos saberes do povo mantem-se vivos e presentes nas lembranças e reminiscências de memórias dos antigos.

Palavras-chave: Palikur-Arukwayene; História; Memória; Narrativa.
\end{abstract}

\section{Arukwayene knowledge path in the waters of history: the emergency of Palikur history in memory narratives}

\begin{abstract}
The Palikur-Arukwayene are an indigenous group living on both sides of Brazil and French Guiana and, together with Karipuna, Galibi-Marworno, and GalibiKalinã, constitute what the literature has called the indigenous peoples from Oiapoque. This paper addresses the emergence of the "historicity" of this people from the narratives of the sages Wet and Tebekwe, and at the same time analyzes how these sages, in a singular and distinct way, are recognized and referenced by this society. The "latency" of Palikur-Arukayene knowledge emerges from the studies and research that have been developed a few years ago with the people and, as a result, foster the (re)writing of history from the intersections with life narratives, experiences, transmission, and sharing the sages' knowledge. In this journey, we have recorded and documented narratives that make it possible to consider that many of the people's kno-
\end{abstract}

\footnotetext{
${ }^{1}$ Doutora em História pela Universidade Federal de Santa Catarina (UFSC). Professora Adjunta da Universidade Federal do Amapá, atuando no Curso de Licenciatura Intercultural Indígena. Membro do Núcleo Kusuvwi de Estudos Palikur-Arukwayene (NUKEPA) e participante do Saberes Indígenas na Escola com o povo Palikur-Arukwayene (e-mail: carina_almaid@yahoo.com.br).

2 Doutora em Linguística pela Universidade Federal do Rio de Janeiro (UFRJ). Professora Adjunta da Universidade Federal do Amapá, atuando no Curso de Licenciatura Intercultural Indígena. Membro do Núcleo Kusuvwi de Estudos Palikur-Arukwayene (NUKEPA) e participante do Saberes Indígenas na Escola com o povo Palikur-Arukwayene (email: elisbarros22@gmail.com).
} 
wledge remains alive and present in the memories and reminiscences of the memories of the ancients.

Keywords: Palikur-Arukayene; History; Memory; Narrative.

\section{DESCOLONIZANDO CERTEZAS: EMER- GÊNCIA DE SABERES A PARTIR DAS ME- MÓRIAS PALIKUR-ARUKWAYENE}

São muitas as latências que permanecem invisíveis e silenciosas ao longo do tempo na trajetória histórica dos povos, na maioria das vezes, sem nunca serem manifestas e desveladas. O conceito de latência, como aqui utilizado, foi emprestado de Gumbrecht (2014) em suas reflexões sobre o pósSegunda Guerra Mundial. O autor destaca a presença invisível das histórias que nunca ouvimos, exemplifica para este conceito que:

“[...] Numa situação de latência, sempre que há um passageiro clandestino, sentimos que existe alguma coisa (ou alguém) que não conseguimos agarrar ou tocar [...]. Além do mais, aquilo que está latente sofre transformações durante o tempo que permanece oculto. Um passageiro clandestino envelhece, por exemplo. Mais importante: não temos razão - ao menos não temos uma razão sistemática - para acreditar que o que quer que tenha entrado num estado latente algum dia virá a revelar-se, ou se não virá a ser esquecido" $(2014$, p.40).

Entre os Palikur-Arukwayene, povo que reside ao longo do curso do rio Urukawá ${ }^{3}$ a

\footnotetext{
${ }^{3}$ É importante salientar que hoje este povo também reside nas cabeceiras do rio Urukawá, nas proximidades da BR-156, situação de vigia decorrente do movimento de controle e gestão de seu território, em consonância com as políticas indígenas adotadas para a proteção da Terra Indígena Uaçá quando da instalação, implantação e atravessamento desta rodovia federal
}

latência do saber permanece e consegue, por vezes, irromper o silêncio. Nesse sentido, este artigo visa problematizar a "memória de velhos" como fator de (re)conhecimento para a (re)escrita da história na sociedade arukwayene. Latência esta que traz consigo, inclusive, a discussão sobre o pertencimento adormecido nos saberes, nas lembranças e nas reminiscências de dois personagens distintos e antagônicos em suas trajetórias de vida, mas que, ao mesmo tempo, são considerados personagens centrais da história do povo. Os senhores Wet e Tebekwe, também conhecidos como Manuel Antonio dos Santos e Manoel Labontê, possuem trajetórias de vida muito diferentes e que a sociedade arukwayene passou a reconhecer, seja pela importância e singularidade do que narram, seja pela narração de novos elementos para a compreensão da história do povo.

A experiência mnemônica de recordar e narrar as histórias aos mais jovens, de geração em geração, como elemento que faz parte da situação de pertencimento, se constitui, hoje, um desafio aos PalikurArukwayene. Na transmissão geracional muitas destas narrativas se perdem no passado histórico e se distanciam do presente cotidiano, histórias essas pautadas em tempos cosmológicos; narrativas que se referem ao saber adormecido nos vínculos xamânicos e nas concepções nativas de compreensão do mundo, não mais recorrente em boa parte da sociedade palikurarukwayene. Nas últimas décadas do século

em suas terras. 
XX os novos caminhos religiosos pentecostais conduziram esta sociedade à adoção de outras crenças que se manifestaram, em muitos momentos, em descompasso e conflitantes com a tradição xamânica e cosmológica. ${ }^{4}$

Os Palikur-Arukwayene compartilham a Terra Indígena Uaçá com outros povos, como os Galibi (Marworno) do rio Uaçá e os Karipuna do rio Curipi. Juntos, foram reconhecidos ao longo do século XX como "indígenas do Oiapoque" e apresentam semeIhanças circunstanciais, como também especificidades socioculturais, decorrentes de suas experiências no processo histórico regional. A narrativa de alteridade estabelece certa assimetria social de pertencimento ameríndio, com discursos que diferenciam os povos indígenas de Oiapoque alimentando a falsa ideia de critérios de indianidade.

O etnólogo Curt Nimuendajú ao conhecer, em 1925, a região do rio Oiapoque e seus afluentes - como a bacia hidrográfica do rio Uaçá, que compreende os rios Urukawá e Curipi -, caracterizou a população indígena do rio Curipi como "brasileiros indianizados" enquanto definiu os Palikur como uma sociedade "em parte miscigenada e creolizada", mas que "ainda conservava em essência a sua velha cultura" (NIMUENDAJÚ, 2001 [1927], p. 194). Transcorridos quase um século entre Nimuendajú e o presente, nos indagamos sobre o significado de suas palavras nas primeiras décadas do século XX sobre as definições de sociedade "indianizada", "miscigenada" e "creolizada" e, sobretudo, as assimetrias sociais que estas palavras expressam.

Sob diversas perspectivas, quando conveniente, ao longo dos anos novecentos os

\footnotetext{
${ }^{4}$ Ver Capiberibe (2007).
}

Palikur-Arukwayene foram considerados pelos agentes da proteção tutelar do Estado brasileiro como os "índios mais atrasados" em comparação aos outros povos indígenas. Contraditoriamente, se há "índios atrasados" é porque há, nas palavras de quem afirma, "índios" que são considerados o inverso disso. Em seu Relatório de Viagem, escrito em julho de 1957, o 1 o tenente médico do Exército Brasileiro, o sr. Dr. José Serur, afirma que visitou a "Vila do Urucauá" e registrou que "[...] não tivemos muito o que ver. São índios atrasados, aliás, os mais atrasados da região". ${ }^{5}$

Atualmente, os estudos sobre protagonismo indígena, imaginários, mentalidades e representações evidenciam que os povos indígenas, na trajetória da história do Brasil, foram envolvidos pela construção de mitografias, compondo os binômios sociais de oposição - como "civilizado versus selvagem" - dentro do que se convencionou chamar de processo civilizatório. ${ }^{6}$ Nesse jogo de sentidos, as categorias que usualmente são recorrentes pelos agentes governamentais da proteção tutelar, bem como pela sociedade circundante, são expressões como "tribo", "índio puro", "mestiço", "civilizado" ou "atrasado". Tais caracterizações evidenciam o desconhecimento acerca

\footnotetext{
${ }^{5}$ Ver Almeida, Oliveira e Oliveira, 2016, p.48.

${ }^{6}$ Nos referimos aqui aos binômios ocidentais que envolveram os ameríndios e que foram consagrados pela historiografia tradicional brasileira, desde o século XIX até boa parte do século XX, como: "selvagens" versus "civilizados", "bravios" versus "mansos", "aliados" versus "inimigos". Alguns pesquisadores discutem na historiografia o papel destes povos ameríndios na história do Brasil, desconstruindo essa visão maniqueísta dos antagonismos. Neste conjunto de escrita da nova história indígena podemos destacar obras importantes como as de John M. Monteiro (1994 e 2001), Maria Regina Celestino de Almeida (2013), Rachel Soihet (2009), João Pacheco de Oliveira (2011 e 2016), entre outros.
} 
da diversidade ameríndia regional, a completa incompreensão e desconsideração quanto aos aspectos socioculturais das sociedades, denominações simplistas que corroboram para justificar a intervenção institucional da "proteção", "assistência" e "nacionalização".

A proteção tutelar ganhou contornos mais definidos com a instalação de dois postos indígenas de atendimento aos povos do Oiapoque pelo Serviço de Proteção aos Índios (SPI) em 1941 e 1942: o Posto Indígena de Fronteira e Vigilância Luiz Horta e o Posto Indígena de Educação e Nacionalização Uaçá, respectivamente. A despeito da intervenção das políticas indigenistas brasileiras engajarem-se para "nacionalizar" os povos do Oiapoque, os Palikur-Arukwayene, falantes da língua Parikwaki, família linguística Arawak, mantiveram sua língua materna. Esse povo, que vive na contemporaneidade tanto no lado brasileiro como na Guiana Francesa, nutria, desde tempos imemoriais, uma intensa rede de relações, principalmente com os franceses, combatidos no passado colonial pelos portugueses. Desde a década de 1940, aparecem em diversos documentos do SPI manifestações governamentais de descontentamento. $\mathrm{O}$ "inspetor de índios" da "ajudância de Oiapoque", ligada a 2a Inspetoria Regional do SPI, Eurico de Melo Cardoso Fernandes, admitiu a dificuldade que tinha em estabelecer relações com os Palikur em virtude das aproximações históricas destes com os franceses. De "índios atrasados" os Palikur passaram a ser vulgarmente conhecidos na região como os "índios puros", sobretudo em virtude da manutenção de sua própria língua. As categorias "índios atrasados" ou "índios puros" servem para deslegitimar a autonomia ameríndia e obscurecer aspectos da história regional, como as relações pretéritas de contatos e conflitos que transcorreram por séculos entre os Palikur e outros povos, como galibi, portugueses, franceses, holandeses, ingleses e, posteriormente, com os ditos brasileiros.

Nos tempos hodiernos, as sociedades indígenas e não indígenas vivenciam a ambivalente existência da memória como elemento de esquecimento, muito embora a contemporânea obsessão comemorativa para eternizar os lugares de memória, que surge nas últimas décadas do século XX, nem sempre seja condizente com a latência do saber adormecido nas sociedades. ${ }^{7}$ Assim como Alves de Seixas (2004, p.17), compreendemos que existam "poros e cicatrizes sociais" que transpiram nas memórias palikur-arukwayene. Nessa perspectiva, e de forma ambivalente, irrompe na condição de latência pelo menos duas condicionantes. A primeira consiste no esquecimento tão habitual nas sociedades, enquanto que a segunda assenta-se no silêncio que se faz conveniente e necessário para todos os povos. Porém, tanto as memórias, como o esquecimento e o silêncio são de cunho intencional e/ou involuntário. É no ato de recordar e narrar que as memórias deixam

\footnotetext{
${ }^{7}$ Essa Expressão "lugares de memórias" está calcada na discussão de Pierre Nora entre o que é história e o que é memória: "[...] A memória é um absoluto e a história só conhece o relativo", com isso a "[...] memória pendura-se em lugares, como a história em acontecimentos" (NORA, 1993, p. 09; p. 24 e 25). A despeito disso, existe uma considerável discussão sobre tais abordagens postuladas por Pierre Nora. Não pretendemos discorrer nessa discussão, mas consideramos sua pertinência nas sociedades hodiernas que estão imbuídas de atos de "rememoração", bem como na construção de lugares de memória; entendemos, por outro lado, que esse movimento pode ser contraditório, uma vez que desvela intencionalmente certos "elementos" da memória e história enquanto obscurece ou não oportuniza o irromper da latência.
} 
a condição de latência e passam a ser protagonistas das histórias do povo. A emergência das reminiscências e lembranças nas memórias dos mais velhos desafia a história dos palikur-arukwayene, uma vez que, como latência, tais memórias passam muitas vezes despercebidas para as novas gerações, como facetas incompreensíveis de sua história.

A emergência dos saberes nas memórias de dois sábios palikur-arukwayene contribui para a desconstrução de certezas históricas. O povo fora nominado pela literatura como "Palikur", contudo, uma questão latente emergiu no atual processo de pertencimento que estão vivenciando, que é o recente ressurgimento do etnônimo "Arukwayene", desvelado pelo povo e problematizado pela linguista Barros da Silva (2016, p.33 - 36). Desde o século XVI existem registros documentais que atestam a existência da "Província Paricura", "Costa de Paricuria", referente ao povo "paricora" ou "paricura", nas proximidades do que se convencionou chamar, posteriormente, de terras do Cabo do Norte, Guiana (Francesa) e, recentemente, costa amapaense (Guiana lusobrasileira).

Conforme destaca o recorrente registro quinhentista do companheiro de esquadra de Colombo, Vicent Pinzón, estes "paricora" se estendiam no período de sua viagem pela margem esquerda da foz do rio Maria Del Mar Dulce, o rio Amazonas. ${ }^{8}$ Contudo, com a gradativa presença dos portugueses nas cercanias da embocadura do Amazonas, e com os emergentes conflitos decorrentes das relações de colonialismo, os "paricora"

\footnotetext{
8 "Il a découvert la mer douce ou l'eau douce, qui va sur une longueur de quarante miles dans la mer; il a également découvert la province qui s'appelle Paricura" (PINZÓN [1513] apud NIMUENDAJÚ, 1926, p.35).
}

desaparecem dos documentos e narrativas coloniais luso-brasileiros, apresentando-se outros povos nativos e suas vicissitudes, a partir de então, contra os invasores. Mas esse "desaparecimento" nos documentos não significou finitude étnica do povo palikur, como ocorreu com tantas sociedades indígenas. Pelo contrário, a territorialidade e a territorialização do povo na região de Oiapoque foram tecidas pelas redes de relações decorrentes dos (re)ordenamentos espaciais, dos movimentos migratórios e das diásporas que se sucederam neste território, hoje Amapá.

Mas a afirmação do etnônimo ocorreu, de fato, no século XX, quando o SPI contribuiu para consolidar, no âmbito do indigenismo brasileiro, o etnônimo "Palikur" ou "Parikur(a)", ${ }^{9}$ no conjunto de povos indígenas brasileiros, possivelmente influenciado por um dos apoiadores da agência, Nimuendajú, que em 1925 empreendeu, por quase cinco meses, uma excursão pelo rio Uaçá, no baixo curso da bacia do rio Oiapoque, circulando e vivendo entre os povos indígenas regionais, sobretudo, entre os "Palikur" (NIMUENDAJÚ, 1926). Em decorrência das consecutivas diásporas estimuladas pelas relações conflituosas dos apresamentos, descimentos, resgates e escravismo impostas pelos portugueses e demais europeus aos diversos povos que viviam entre a foz do Amazonas e o Cabo Orange, os Palikur-Arukwayene vieram a se situar, restrita e especificamente, no curso do rio Urukawá, no lado brasileiro, e em certas localidades da Guiana Francesa, como Trois Paletuviers, às margens do rio Oiapoque e Macouria, ambas no território francês.

\footnotetext{
${ }^{9}$ Os documentos do SPI, a partir da década de 1940 em diante, apresentam várias grafias para o nome do povo, como paricur ou parikur(a), pariukur(a), entre outros.
} 
Ainda que os registros nas carteiras de identidade evidenciem que tanto Wet como Tebekwe nasceram na década de 1930, os sábios palikur-arukwayene carregam consigo muito mais que o peso da idade, trazem a experiência de mais de oitenta anos de vida repleta de suas latências. Nas narrativas de Wet e Tebekwe existe a memória voluntária, àquela que emerge da uniformidade histórica, mais corriqueira e superficial, ligada a experiência imediata e, de certa forma, consciente; como também existe a memória involuntária, que reside na espontaneidade do momento, independente da vontade de lembrar. Essa memória é mais elevada, real e espontânea, se traduz em imagens que aparecem e desaparecem, em lampejos bruscos que batem com o passado sem se ter feito um esforço consciente para isso. ${ }^{10}$ Ambos os narradores recorrem a memória voluntária, mas os momentos mais significativos para a desconstrução de certezas históricas na trajetória e cosmologia do povo reside na emergência das memórias espontâneas e involuntárias que irrompem da latência. Quando conversam, os narradores parecem esquecer os equipamentos audiovisuais, gesticulam, cantam, marejam os olhos, silenciam em determinadas falas e sorriem como se estivessem diante do passado, sempre narrando na língua de seus ancestrais.

O passado tem seus caminhos que jamais serão conhecidos pelas sociedades, mas o passado deixa suas reminiscências. Senti-

\footnotetext{
${ }^{10}$ A historiadora Jacy Alves de Seixas esclarece que a memória é "[...] algo que 'atravessa', que 'vence obstáculos', que 'emerge', irrompe: os sentimentos associados a este percurso são ambíguos, mas estão sempre presentes.", portanto, a memória voluntária deixa escapar a dimensão "[...] afetiva e descontínua da vida e das ações dos homens." (2004, p. 47).
}

mentos, ideias, recordações, lembranças e memórias são tudo aquilo que procuramos, já que o passado, por si, está noutro tempo e espaço, por certo, intangível. Desde que passamos a documentar as narrativas, os horizontes de finitude dos estudos acerca da "pretensa história" parecem se distanciar. Há algum tempo percorremos as águas escuras do Urukawá para adentrar nas águas turvas da história do povo. Estamos registrando as narrativas que os antigos contam, ou, as memórias de Wet e Tebekwe, dois personagens reconhecidos como homens que "sabem" e conhecem o passado palikur-arukwayene.

O percurso da pesquisa iniciou-se ainda em 2010, com os trabalhos de documentação, são desse período as primeiras narrativas coletadas. Ao longo dos anos a pesquisa foi se tornando mais profunda, regular e abrangente, focando, além da documentação, transcrição e tradução das narrativas, na realização de estudos, oficinas e (res)significações, durante as quais os Palikur-Arukwayene têm desconstruído certezas no âmbito da história do povo e no contexto de pertencimento. Cada um desses narradores, embora detentores de uma tradição comum, também carregam sua própria subjetividade, sua própria experiência.

Tebekwe e Wet são personalidades singulares, o primeiro tem reconhecimento social, suas origens e história de vida se acomodam com as instâncias de pertencimento étnico. A história de vida de Wet seguiu outros caminhos, de um pertencimento à margem da história, mas que o conduziu ao reconhecimento de seu povo. Inspirando-nos em Benjamim (1987, p.198199) podemos dizer que Tebekwe é o narrador que viaja e tem muito a contar, admi- 
rado pelo seu povo como alguém que transita entre o perto e o longe; por outro lado, Wet se parece com o homem "que ganhou honestamente sua vida" sem nunca ter saído do seu lugar e que "conhece suas histórias e tradições". Essas duas figuras de narrador, "representantes arcaicos", equilibram-se na significação de seus relatos. Nessa perspectiva benjaminiana, esses relatos a que recorre os narradores são oriundos da experiência "que passa de pessoa a pessoa". Estas trajetórias de vida, apesar de muito distintas, representam as múltiplas faces do que vivenciaram os PalikurArukwaynene no decorrer do século XX. As sinuosidades destes personagens indígenas serão o fio condutor para a compreensão da emergência de latências e da reescrita da história deste povo.

\section{MANOEL LABONTÊ: A HISTÓRIA COMO FATOR DE PERTENCIMENTO}

Manoel Labontê ou Tebekwe é apontado

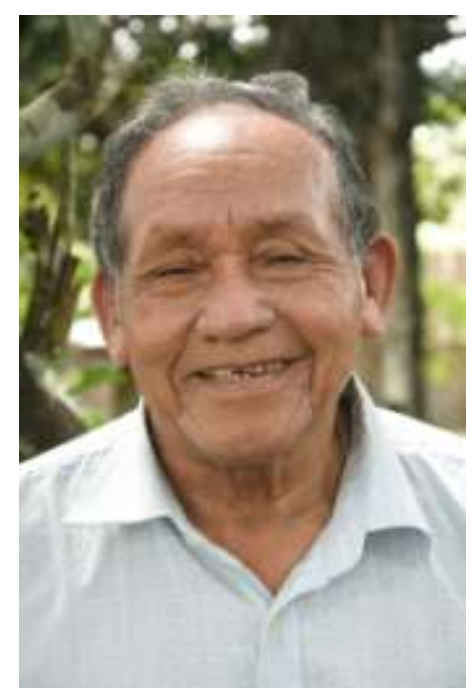

Imagem 1: Retrato do sábio Tebekwe por muitos indígenas e não indígenas como um homem de considerável conhecimento, principalmente em decorrência do domínio e facilidade de se expressar tanto em parikwaki quanto nas línguas kheuól $^{11}$, português e francês.

11 Língua crioula falada pelos Karipuna e GalibiMarworno. Muitos Palikur-Arukwayene, principalmente os idosos, possuem domínio desta língua.
Dessa forma Tebekwe tem sido, ao longo dos anos, um reconhecido interlocutor de diversos estudos sobre os Palikur, pois, ao contrário da grande maioria de seu povo, domina tanto as línguas regionais quanto as ambiguidades do mundo que o cerca. Como intermediador e "interprete" das histórias, memórias e saberes ao mundo não indígena, sua trajetória é repleta de interculturalidade e protagonismo.

Manoel nasceu, possivelmente, em 1930, entre os Palikur de Saint Louis, portanto, é considerado cidadão francês, tendo sido registrado como Claude. Enquanto Claude, costumava acompanhar seu pai no comércio e extração de produtos regionais diversos e cobiçados pelos franceses, como pau rosa ou "bois du rose" e as peles/couros de jacaré-açú. Em função do decréscimo comercial francês, Claude foi viver com a família no rio Urukawá, onde passou a ser conhecido por Tebekwe. Era jovem quando algumas epidemias começaram a assolar a vida dos Palikur na região e, por isso, decidiu residir, sozinho, entre os Karipuna da Aldeia Santa Isabel, no rio Curipi, os quais o chamavam de Manoel.

Claude/Tebekwe/Manoel chegou a conhecer os antigos agentes e chefes do indigenismo que atuaram na região do Oiapoque. Também viveu e trabalhou no Encruzo, local onde se situou, por algum tempo, a sede do Posto Indígena Uaçá, na confluência do rio Curipi com Uaçá. Neste local o SPI construiu uma estrutura produtiva para a promoção dos pressupostos do indigenismo brasileiro, com atração, assistência e nacionalização de comunidades indígenas em situação de fronteira. Manoel frequentou uma das escolas implementadas pela proteção tutelar, na Aldeia Santa Isabel, onde, junto com outros indígenas, era obrigado a 
escrever e a falar, fluentemente, o português.

Nas sociedades indígenas aquele que narra sob diversas perspectivas a(s) história(s) de seu povo adquire considerável respeitabilidade, sendo reconhecido como "historiador" ou pessoa que narra histórias. ${ }^{12}$ Ao contrário do mundo ocidental hodierno, a narrativa histórica ameríndia se sustenta na oralidade das reminiscências mnemônicas, não sendo desafiada ou desconsiderada por não estar escrita, ainda que, felizmente, muitos indígenas pesquisadores e/ou professores estejam registrando na forma de documento escrito e audiovisual a historicidade de suas trajetórias.

Entre os Palikur-Arukwayene o ato de narrar o passado, costumeiramente, se destina àquelas pessoas mais velhas da aldeia ou àquelas com significativa respeitabilidade social. O lugar de fala não é questionado e sustenta a narrativa, delegando-Ihe veracidade e verossimilhança. Uma característica comum deste povo é que estes se furtam de adotar a postura de narrador, sempre indicando um grupo seleto de homens ${ }^{13}$ que seriam os "detentores" de seus conhecimentos e saberes. Manoel está entre eles! Inegavelmente, isso ocorre porque, além de "historiador", com uma memória "singular", ele tem facilidade em se expressar em diversas línguas, o que facilita sua interlocução com os pesquisadores que intentam

\footnotetext{
${ }^{12}$ A palavra "historiador" empregada aqui não é equivalente ao conceito contemporâneo que a palavra adquiriu com o desenvolvimento da ciência História, do fazer e saber histórico e historiográfico.

${ }^{13}$ As mulheres palikur não costumam ser identificadas como "historiadoras", ainda que suas memórias tenham vivacidade e apresentem elementos e sinuosidades do mundo feminino que as memórias dos homens jamais alcançariam.
}

estudar e compreender o universo palikur. Foi assim com Lux Vidal, Artionka Capiberibe, Marlui Miranda, Eduardo Góes Neves, David Green, Eneida Corrêa de Assis, María del Pilar Miguez Fernández, Nicanor Rebolledo Recendiz, entre outros. Nessa perspectiva, sua história de vida se mistura com as noções de alteridade, identidade e pertencimento, pois Manoel, além de ter reconhecimento social e étnico entre os seus, possui considerável prestígio e uma forte rede de relações externas.

É importante ressaltar na história de vida de Tebekwe que sua genealogia já Ihe resguarda, entre seu povo, a condição de pertencimento: o narrador é filho de mãe e, sobretudo, de pai palikur, portanto, Tebekwe é, reconhecidamente, Palikur. Para este povo a origem e o clã são transmitidos de forma hereditária, através da patrilinearidade, ou seja, para ser considerado Palikur é necessário ser filho de pai palikur.

\section{WET: PERTENCIMENTO À MARGEM DA HISTÓRIA}

Em 2016, Wet realizou em sua Aldeia Mawihri a Kayka Aramtem, um ritual em homenagem ao kayg (lua), e que havia sido eclipsado, pois não era celebrado há quase quatro décadas. ${ }^{14}$ Os preparativos tornaram-se momentos de aprendizagem para os Palikur-Arukwayene, pois Wet preocupouse em ensinar todas as etapas necessárias para a festa, preocupado com a continuida-

\footnotetext{
14 Esse "esquecimento" é relativo, poderíamos pensar que ocorreu um processo de "silenciamento" acerca das manifestações socioculturais do povo com a adoção de novas crenças religiosas, de base pentecostal. A Kayka Aramtem não foi esquecida pelos mais velhos, bastando que a latência irrompa para que os elementos desta festa ressurjam, inclusive, com maior vitalidade.
} 
de da transmissão dos conhecimentos tra-

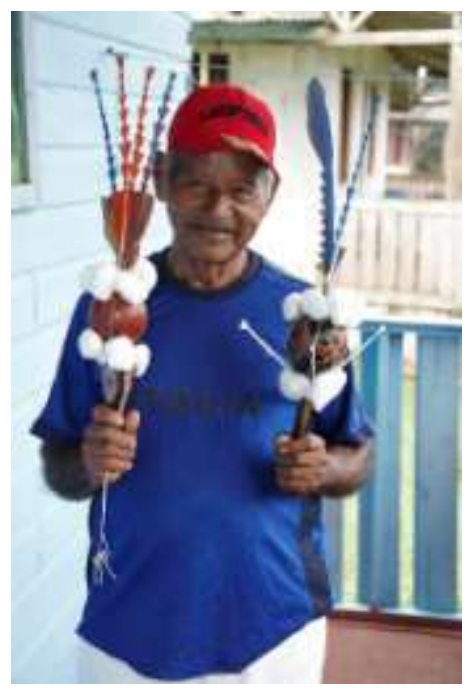

Imagem 2: Retrato do sábio Wet dicionais de seu povo. Ninguém pôs em dúvida o saber de Wet, muito menos sua autonomia e autoridade para a realização de tão importante ritual. Por isso mesmo, foi com muita surpresa que ouvimos, durante os preparativos, uma frase proferida por um dos parentes próximos deste sábio:

- Wet não é Palikur!

Aquela negativa quanto ao pertencimento do sábio Wet nos causou estranhamento. Aos olhos de um leigo pode parecer incompreensível, para não dizer contraditório, que um homem detentor de significativa sabedoria e narrador minucioso de inúmeras histórias do seu povo tenha sido considerado entre os seus, em boa parte da vida, como um "parnah" ${ }^{15}$ ". Foi o que ocorreu com Wet! Contudo, é preciso problematizar que a patrilinearidade é um elemento fundamental no ethos de pertencimento e alteridade dos Palikur-Arukwayene.

Wet foi registrado como Manoel Antonio dos Santos. Nasceu na década de 1930, numa pequena ilha localizada no rio Urukawá, sua trajetória de vida apresenta sinuosidades e episódios de luta e autodeterminação. Filho de uma Palikur com um parnah, foi criado pela família materna, tendo ficado aos cuidados dos avós após a morte

\footnotetext{
${ }^{15}$ Este é o termo utilizado pelos Palikur-Arukwayene para se referir aos não-indígenas.
}

precoce de sua mãe. Assim, conviveu e aprendeu muito com seu avô, Kiyomni Labontê, que era xamã, e quem Ihe atribuiu o nome de um pequeno pássaro, chamado Wet.

A história pessoal de Wet conforma-se com as vicissitudes enfrentadas por seu povo em boa parte do século XX. Os Palikur experienciaram epidemias, mortes, castigos, intimidação e medo, além de desentendimentos e cenas mais austeras e contraditórias da atuação do SPI. Wet viveu duras lições de vida, tendo sido obrigado a "trabalhar" para o SPI no Encruzo (PI Uaçá), durante um exílio compulsório de dois anos.

A cultura imaterial arukwayene se materializa com o saber-fazer deste sábio, através de significativas expressões: as formas em madeira que esculpe e as históriasmemórias que narra. Wet narra - pois não sabe escrever - para romper o esquecimento, objetiva que as ações de seu povo não se percam ou, ainda pior, que não sejam desconhecidas às novas gerações.

Há tantas "histórias" a se considerar como há tantos narradores envolvidos por suas próprias formas de "historicizar". Nesse sentido, Veyne (2014, p.27) explica que Heródoto se divertia relatando as diferentes tradições contraditórias, enquanto Tucídides procurava relatar aquela história que considerava verdadeira. No livro "Os gregos acreditavam em seus mitos" o historiador mostra, no mínimo, que os distintos povos têm formas próprias e autônomas de contar e narrar suas histórias, que podem ser resumidas pelos mais desatentos como "mitologia": "Os gregos têm uma maneira própria de acreditar em sua mitologia ou de ser céticos, e essa maneira aparece apenas falsamente com a nossa. Eles têm também sua maneira de escrever a história, que não é a 
nossa [...]" (2014, p.16).

Assim como os gregos tem maneiras próprias de contar e escrever a história, os Palikur-Arukwayene também as têm. As "histórias" que Wet compartilha parecem "incompreensíveis" fora do contexto mitológico e cosmológico, desafiam a racionalidade histórica à evocar suas latências, seus esquecimentos, seus silêncios e silenciamentos, por certo, suas memórias e reminiscências. Ao contrário de Tebekwe, Wet não se expressa em português, seus pensamentos e palavras são sempre em parikwaki ou kiapunka, a "língua dos antigos", como os Palikur-Arukwayene costumam explicar. Dessa forma, acessar e compreender o universo das narrativas de Wet exige de seus interlocutores um amplo conhecimento linguístico e também sociocultural, que possibilite submergir no mundo do narrador, além de um considerável domínio do português, que permita traduzir nesta língua os complexos sentidos do discurso de Wet.

Entre ser ou não considerado um Palikur, Wet passou a receber reconhecimento e respeitabilidade pelo conhecimento que externa de suas memórias e histórias. As memórias de Wet revelam um mundo arukwayene que estava submerso nas profundezas da experiência de alteridade dos Palikur e, nesse sentido, evidenciam a emergência e a lucidez da historicidade descolonizadora. Da condição de pertencimento à margem da história do povo, o sábio Wet passou, nos últimos anos, a ser reconhecido como o "google" dos PalikurArukwayene. Essa mudança de reconhecimento não tem sido simples, nem fácil, nem imediata, mas é consequência, também, do acesso que os Palikur-Arukwayene tem tido à Universidade, onde são instigados a pes- quisar e contar a trajetória histórica de seu povo, o que, obrigatoriamente, perpassa pela memória dos mais velhos. Nosso mestre, o "sábio das estrelas", cumpriu sua missão entre nós em junho desse ano. Wet subiu no Kusuvwi e hoje está no céu, ajudando a jogar água pela terra, enchendo o Urukawá de vida e esperança.

\section{CONSIDERAÇÕES FINAIS}

A latência e o esquecimento, sejam eles voluntários ou não, são duas faces da sociedade arukwayene. Os sábios Tebekwe e Wet representam instâncias diacrônicas da história. Suas memórias-narrativas distintas e, por vezes, antagônicas, equilibram, de uma ponta a outra, a diversidade e a complexidade da sociedade palikurarukwayene. Da necessidade de falar, condição de quem tem muito a dizer, esses dois narradores se preocupam em compartilhar e perpetuar suas memórias com os seus, com as novas gerações e com os "outros", "re-escrevendo" a história do povo. Tebekwe e Wet estão imbuídos pelo devir da história!

Certos elementos socioculturais que fundamentam o pertencimento, como a patrilinearidade, ainda influenciam a organização da sociedade palikur-arukwayene. Esses elementos ressaltam a continuidade dos vínculos identitários, que quando não estão em descompasso com o processo de renovação religiosa, permanecem e indicam que tudo que se relaciona com a cosmologia e o xamanismo passou a ser reservado ao silêncio, resguardado ao estado de latência, podendo emergir e deflagrar situações de conflitos ou não.

Inegavelmente, os Arukwayene foram impactados pelo processo missionário pen- 
tecostal da segunda metade do século $X X$, sem embargo, quando boa parte da sociedade regional e dos pesquisadores acreditavam que as camadas de esquecimento haviam obscurecido a história do povo, eis que as memórias dos sábios arukwayene desvelam a todos a presença do "ser".

As trajetórias ameríndias envoltas por águas turvas e nebulosas da "história colonizadora" foram, em grande parte, desconsideradas no processo de construção geopolítica dos territórios latino-americanos. A emergência do protagonismo ameríndio, como elemento de autonomia e de diversidade nas narrativas discursivas da história latino-americana, consiste num fenômeno recente, que percorre outros caminhos interpretativos para a compreensão dos mundos indígenas e não indígenas, envolvidos na tessitura do que se convencionou chamar de "América".

Paulatinamente, muitos povos rompem com esse pensamento ocidental e desvelam narrativas de história a partir de suas próprias categorias de saber, presentes em latentes experiências de memória dos sábios indígenas. Os Arukwayene vivenciaram, ao longo de séculos, forte pressão sociopolítica e territorial. É nesse sentido que a emergência da historicidade nas memórias de seus sábios possibilita adentrar no universo complexo de seu mundo. Assim, marcados pelas singularidades atribuídas aos povos de tradição Arawak, os caminhos do saber arukwayene se apresentam nas narrativas de memórias dos mais velhos.

\section{REFERÊNCIAS}

ALMEIDA, Carina S. de.; OLIVEIRA, Leonia R.; OLIVEIRA, Lilia R. Atuação do Serviço de Proteção aos Índios entre os Povos Indíge- nas de Oiapoque. IN: BRITO, A. U.; DALMÁCIO, C. E. da C.; SIMÕES, H. C. G. (Org.). Ciências Humanas: resultados dos projetos de iniciação científica da Universidade Federal do Amapá/UNIFAP. Macapá: Ed. UNIFAP, 2016. p.41-66.

ALMEIDA, Maria Regina Celestino de. Metamorfoses indígenas. Identidade e cultura nas aldeias coloniais do Rio de Janeiro. 2a Ed. Rio de Janeiro: Ed. FGV, 2013.

BARROS DA SILVA, Elissandra. A língua Parikwaki (Palikur, Arawak): situação sociolinguística, fonética e fonologia. Tese de Doutorado, Programa de Pós-Graduação em Linguística da Universidade Federal do Rio de Janeiro (UFRJ), 2016.

BENJAMIN, Walter. Sobre o conceito de história. In: Magia e técnica, arte e política. v.1. 5 ed. São Paulo: Brasiliense, 1993.

CAPIBERIBE, Artionka. Batismo de fogo: os Palikur e o cristianismo. São Paulo: Annablume; Fapesp; Nuti, 2007.

GUMBRECHT, Hans Ulrich. Depois de 1945. Latência como origem do presente. São Paulo: EDUNESP, 2014.

MONTEIRO, John Manuel. Negros da terra: índios e bandeirantes nas origens de São Paulo. São Paulo: Companhia das Letras, 1994.

MONTEIRO, John. Tupis, Tapuias e os historiadores: Estudos de História Indígena e do Indigenismo. Tese Apresentada para o Concurso de Livre Docência Área de Etnologia, Subárea História Indígena e do Indigenismo. Campinas, 2001. Disponível em: <http:// www.ifch.unicamp.br/ihb/estudos/TupiTap uia.pdf>. Acesso em: junho de 2009. NIMUENDAJÚ, Curt. Excursões pela Amazônia, 1927. Revista de Antropologia, São Paulo, USP, 2001, v. 44, n. 1, pp. $189-200$. NIMUENDAJÚ, Curt [1926]. Les Indiens Pa- 
likur et leus voisins. Présentacion et notes de Pierre Grenand. Encyclopédie palikur fascicule 1. France: Université d'Orléans.

NORA, Pierre. Entre memória e história. A problemática dos lugares. Projeto História, São Paulo, 1993, n.10, pp.07 - 28.

OLIVEIRA, João Pacheco de (Org.). A presença indígena no Nordeste: processos de territorialização, modos de reconhecimento e regimes de memória. Rio de Janeiro: Contra Capa, 2011.

OLIVEIRA, João Pacheco de. 0 nascimento do Brasil e outros ensaios: "pacificação", regime tutelar e formação de alteridades. Rio de Janeiro: Contra Capa, 2016.

SEIXAS, Jacy Alves. Percursos de memórias em terras de história: problemáticas atuais. In: BRESCIANI, Stella; NAXARA, Márcia. (Org.) Memória e (re)sentimento. Indagações sobre uma questão sensível. 2 ed. Campinas: Ed.UNICAMP, 2004. p. 37-58.

SOIHET, Rachel. et al. Mitos, projetos e práticas políticas: memórias e historiografia. Rio de Janeiro: Civilização Brasileira, 2009. VEYNE, Paulo. Os gregos acreditavam em seus mitos? Ensaio sobre a imaginação constituinte. São Paulo: Editora Unesp, 2014. 